\title{
Optimal angle of needle insertion for spinal anesthesia in patients with spondylolisthesis: an ultrasonographic study
}

\author{
Youngwon Kim', Seokha Yoo ${ }^{1}$, Sun-Kyung Park ${ }^{1}$, Hansu Bae ${ }^{2}$, Young-Jin Lim and Jin-Tae Kim*
}

\begin{abstract}
Background: Spondylolisthesis is a common degenerative spinal deformity. At the level of spondylolisthesis, the anatomy of the interlaminar space may differ from normal spine, in which case optimal angle of the needle insertion for spinal anesthesia may change. This study compared the optimal angle of needle insertion during spinal anesthesia in patients with and without lumbar spondylolisthesis using ultrasound.

Methods: We recruited 40 patients, 20 with and 20 without lumbar spondylolisthesis (group S and N, respectively). Ultrasonography was performed in the transverse midline and parasagittal oblique views at the spondylolisthesis level and the adjacent upper level. We measured the probe application angle with the longest interlaminar height of the ligamentum flavum-dura mater complex (LFD), depth from the skin to the LFD, depth from the skin to the anterior complex, and intrathecal space width. A positive angle represented a cephalad angulation.

Results: The optimal needle insertion angle in the transverse midline view at the spondylolisthesis level was (-) $2.7 \pm 3.4^{\circ}$ in group $S$ and $0.8 \pm 2.5^{\circ}$ in group $N(P<0.001)$. In the parasagittal oblique view, it was $(-) 2.7 \pm 4.5^{\circ}$ in group $S$ and $1.0 \pm 3.2^{\circ}$ in group $N(P=0.004)$. There were no between-group differences in the angles at the upper level, with all cephalad angles in both views. Other ultrasound image data were comparable between groups.
\end{abstract}

Conclusion: In patients with spondylolisthesis, caudad angulation of the spinal needle can aid successful spinal puncture at spondylolisthesis level, both in the midline and paramedian approaches.

Trial registration: www.ClinicalTrials.gov (NCT04426916); registered 11 June 2020.

Keywords: Spinal anesthesia, Spondylolisthesis, Ultrasonography

\section{Background}

Spinal anesthesia has been traditionally performed based on surface anatomical landmarks. Recently, however, with the widespread use of ultrasonography during spinal anesthesia, an approach based on individual anatomical characteristics has emerged [1, 2]. Ultrasonography facilitates spinal anesthesia, especially in patients with

\footnotetext{
*Correspondence: jintae73@gmail.com

${ }^{1}$ Department of Anesthesiology and Pain Medicine, Seoul National University Hospital, Seoul National University College of Medicine, Daehak-ro, Jongno-gu, Seoul, Korea 03080

Full list of author information is available at the end of the article
}

anatomical abnormality of spine, by providing characteristic anatomic information $[3,4]$.

Considering the angles of the spinous process and interlaminar space during lumbar flexion, it is recommended that the spinal needle should be inserted at a slight cephalad angle for successful spinal puncture [5]. However, it may not be possible to apply this approach in patients with spinal abnormalities such as spondylolisthesis. In patients with spondylolisthesis, the anatomy of the interlaminar space through which the needle passes during spinal anesthesia can be altered due to the angles formed by the two vertebral bodies and spinous processes 
[6]. Therefore, the optimal angle of needle trajectory in these patients may be different from that in the general population $[7,8]$.

Spondylolisthesis is commonly observed in the elderly undergoing spinal anesthesia [9]. However, the anatomical characteristics to be considered during spinal anesthesia in patients with spondylolisthesis have rarely been studied [10]. Ultrasound images can provide anatomical information that can guide the selection of the optimal angle and point of spinal needle insertion. The aim of this study was to determine whether there is a difference in the optimal angle of spinal needle insertion during spinal anesthesia between patients with spondylolisthesis and those without spondylolisthesis.

\section{Methods}

\section{Study design}

This trial was approved by the institutional review board of Seoul National University Hospital (No. 2005-1491125 ) and written informed consent was obtained from all subjects participating in the trial. The trial was registered prior to patient enrollment at ClinicalTrials.gov (NCT04426916, Principal investigator: Jin-Tae Kim, Date of registration: 11 June 2020.)

From June to August 2020, we enrolled adult patients with an American Society of Anesthesiologists physical status of I-III who were scheduled for elective surgery at Seoul National University Hospital, Seoul, Republic of Korea. The first patient was enrolled in June, 23, 2020. Total of 40 participants, 20 patients with singlelevel spondylolisthesis (group S) and 20 patients with normal spinal anatomy (group N) were recruited. The sample size was set empirically by referring to previous studies comparing the distance on ultrasound images [11-13]. Lumbosacral spinal X-ray image were taken in all patients scheduled for surgery under spinal anesthesia for preoperative evaluation. Based on the preoperative X-ray images, patients with spondylolisthesis at only one lumbar level were screened and enrolled in group S. Patients without spondylolisthesis were enrolled in group $\mathrm{N}$, and patients in group $\mathrm{N}$ were selected in a way that they were of the same gender, within $10 \%$ of the age, $10 \%$ of the height, and $15 \%$ of the weight of patients with spondylolisthesis. We excluded patients who had difficulty achieving the lateral decubitus position for spinal anesthesia, a history of lumbar spine surgery, serious spinal anatomical deformities other than spondylolisthesis, or spondylolisthesis at more than one level. All patients provided written informed consent prior to participation.

\section{Ultrasonography procedure}

All participants underwent preoperative spinal ultrasonography in a curtained waiting room or an operating room. Ultrasonography was performed by an anesthesiologist (YK) with experience of performing ultrasoundassisted spinal anesthesia in more than 50 cases. The C5-2 s convex array (frequency range: $2-5 \mathrm{MHz}$ ) of a TE7 Touch Enabled Ultrasound System (Mindray, Shenzhen, China) or the C1-5 convex array of a Venue Go $^{\text {TM }}$ (GE Healthcare, Chicago, IL) was used for scanning. A pillow was placed under the patient's head in the lateral decubitus position to align their spine and their knees were bent toward their chest with neck flexion to attain the best position for spinal anesthesia. Ultrasonography was performed in the midline transverse and paramedian sagittal oblique views at the level of the spondylolisthesis (e.g., L4 on L5, L4/5) and the adjacent upper level (e.g., L3/4); thus, four images were obtained for each patient.

First, we used the transverse midline view to identify and mark the tips of the spinous processes on the skin and drew the neuraxial midline by connecting the tips and determined the interspinous spaces. The probe was then placed at the middle of the interspinous space, where the anterior complex (AC) and LFD were visible in a plane perpendicular to the back. At the point, the probe was tilted cephalad or caudad with respect to perpendicular plane to determine the angle at which the LFD was the longest. This point and angle were regarded as the "expected optimal needle insertion point and angle" of transverse midline approach for successful spinal anesthesia. The angle between the central axis of the lateral face of ultrasound probe and the patient's back at the expected needle insertion point was measured using a protractor (Fig. 1). If the ultrasound probe was tilted cephalad at the longest observed LFD, the angle was marked as positive, and if it was tilted caudad, the angle was marked as negative. The ultrasonography image in the paramedian sagittal oblique view was obtained on the dependent side by placing the ultrasound probe lateral to the midline and tilting it medially. The level of each interlaminar space was confirmed by counting up from the sacrum [11]. The expected optimal needle insertion angle was measured using the same method that was used for the transverse midline view (Fig. 1). The probe was placed at where the AC and LFD were visible and was tilted cephalad or caudad to determine the angle at which the interlaminar height of the LFD, defined as the length of the hyperechoic line visible through the interlaminar space, was the longest. The angle between the central axis of the frontal face of probe and patient's back was measured. In the patients in group $\mathrm{N}$, the angle was measured at a level corresponding to the spondylolisthesis level of the patient in group $\mathrm{S}$ with whom they were matched. Using the obtained images, the interlaminar height of 

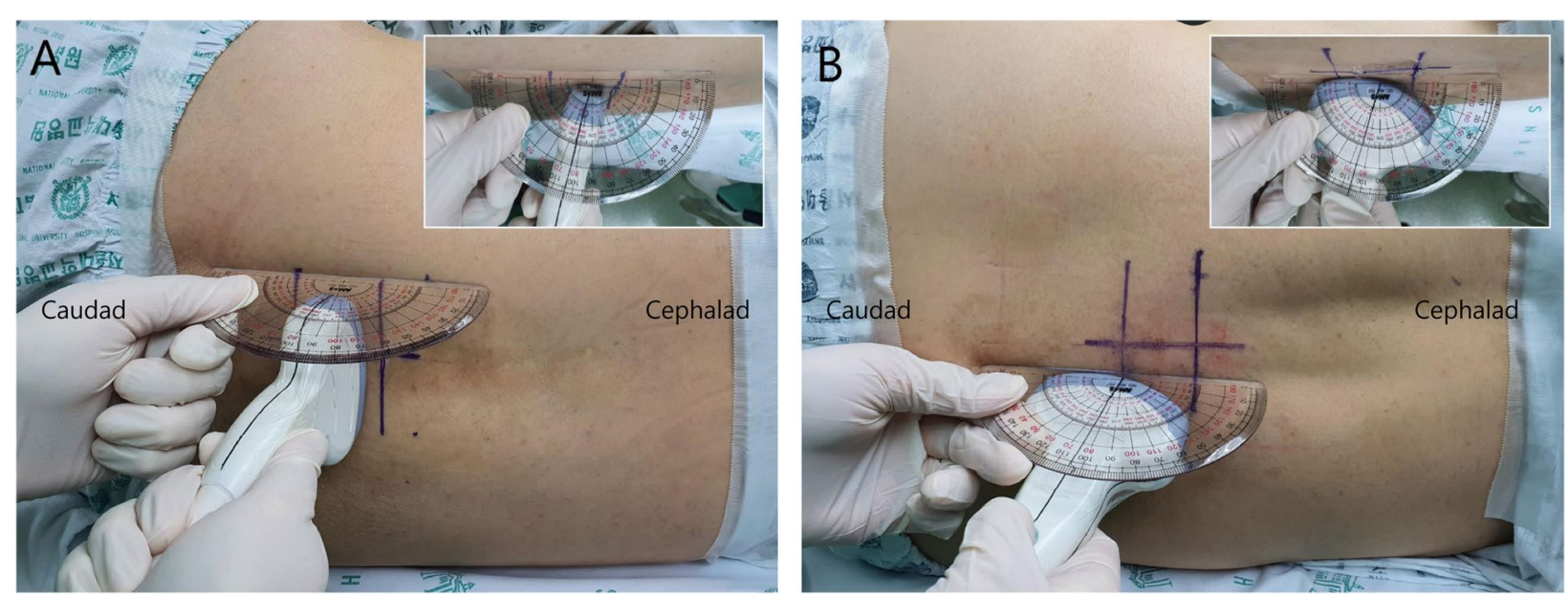

Fig. 1 The method of angle measurement at transverse midline view and parasagittal oblique view. (A) The ultrasound probe was placed transverse to the patients'back and was tilted toward cephalad or caudad to find the longest observed the ligamentum flavum-dura mater complex (LFD) height. The probe application angle with the longest interlaminar height of LFD was measured using a protractor. The measured angle was $(+) 14^{\circ}$ in this image. (B) The ultrasound probe was placed in the parasagittal plane with a medial tilt towards the midline. The probe is tilted toward cephalad to caudad, and the probe application angle with the longest interlaminar height of LFD was measured using a protractor. The measured angle was $(+) 15^{\circ}$ in this image

the LFD, depth from the skin to the LFD, depth from the skin to the $\mathrm{AC}$, and width of the intrathecal space (distance between LFD and AC) were measured. Another anesthesiologist who was blinded to group allocation performed these measurements. Representative ultrasound images of the transverse midline and parasagittal oblique view with measurements are shown in Fig. 2.

\section{Outcome assessment}

The primary outcome was the angle between the central axis of the ultrasound probe and the patient's back at the point at which the interlaminar space was widest in the midline transverse and paramedian sagittal oblique views at the level of the spondylolisthesis. Secondary outcomes included the angles measured using same method at
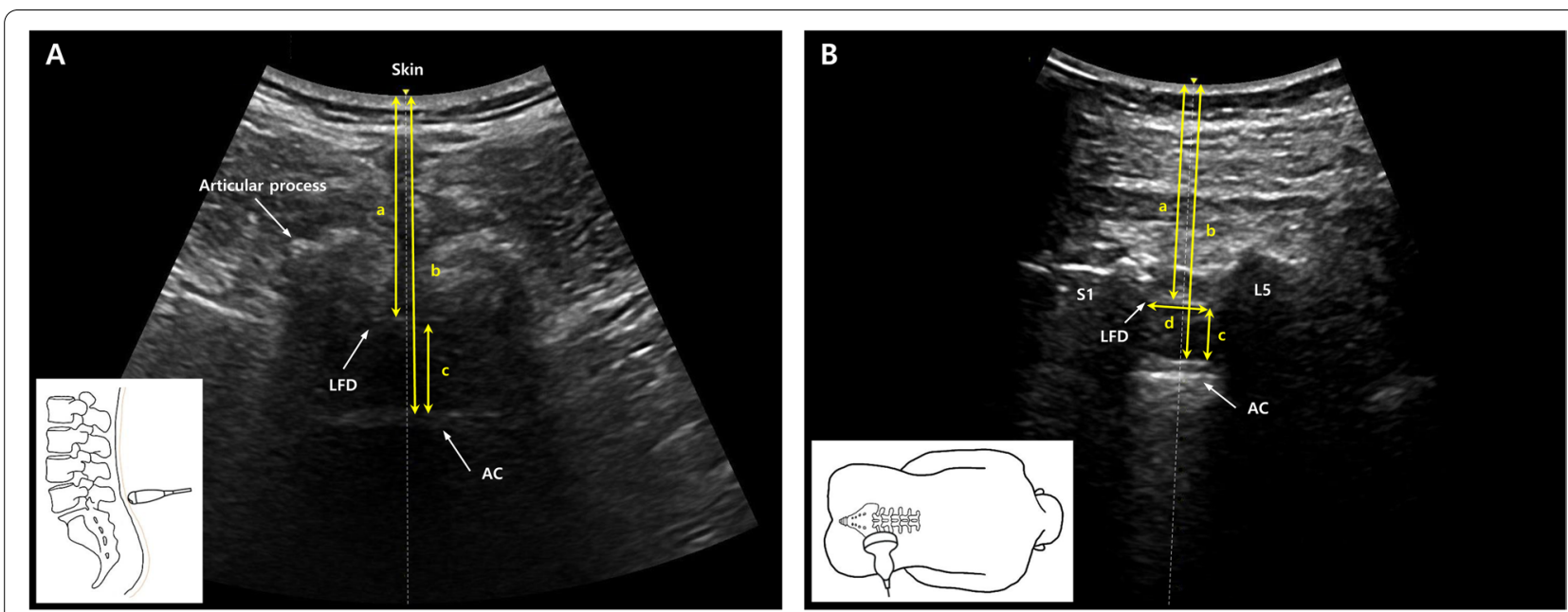

Fig. 2 Spinal ultrasound image. (A) Spinal ultrasound image of transverse midline view of a spondylolisthesis patient at the level of L5-S1. As shown in the small schematic diagram at the left bottom of the ultrasound image, the image was taken with the ultrasound probe tilted toward caudad direction. (B) Spinal ultrasound image of parasagittal oblique view of a spondylolisthesis patient at the level of L5-S1. As shown in the small schematic diagram at the left bottom of the ultrasound image, the image was taken with the ultrasound probe tilted toward caudad direction, with a medial tilt to midline. LFD: Ligamentum flavum-dura mater complex. AC: Anterior complex. a: Depth from skin to the LFD. b: Depth from skin to the AC. c: Width of the intrathecal space (distance between LFD and AC). d: Interlaminar height of the LFD 
the adjacent upper level of the spondylolisthesis and the interlaminar height of the LFD, depth from the skin to the LFD, depth from the skin to the AC, and width of the intrathecal space (distance between LFD and AC) at each level and view.

All methods were carried out in accordance with relevant guidelines and regulations.

\section{Statistical analysis}

Continuous data were tested for normality using the Kolmogorov-Smirnov and Shapiro-Wilk tests. Normally distributed data were compared using the Student $\mathrm{t}$-test (mean $\pm \mathrm{SD}$ ), and non-normally distributed data were compared using the Mann-Whitney test (median [interquartile range]). A two-tailed $P<0.05$ was considered statistically significant. Categorical data were collated as numbers and percentages and compared using $X^{2}$ test or Fisher's exact test. Data were analyzed using SPSS Statistics version 25.0 (IBM Corp., NY, USA).

\section{Results}

A total of 40 patients (20 per group) were recruited for this study. The patients' demographic characteristics are shown in Table 1. There were no differences between the two groups. All the patients in group $\mathrm{S}$ had grade 1 spondylolisthesis according to the Meyerding classification [14]. The spondylolisthesis levels were as follows: L3/4 in four, $\mathrm{L} 4 / 5$ in seven, and L5/S1 in nine patients.

The optimal angles of needle insertion at the level of the spondylolisthesis and the adjacent upper level are shown in Table 2. The mean of the optimal needle insertion angle at the level of the spondylolisthesis in the transverse midline view was (-) $2.7 \pm 3.4^{\circ}$ in group $S$ and $0.8 \pm 2.5^{\circ}$ in group N (mean difference -3.6 (95\% CI (-) 5.5 to (-) 1.6), $P<0.001)$. In the parasagittal oblique view, the angle was (-) $2.7 \pm 4.5^{\circ}$ in group $\mathrm{S}$ and $1.0 \pm 3.2^{\circ}$ in group $\mathrm{N}$ (mean difference -3.7 (95\% CI (-) 6.2 to (-) 1.2), $P=0.004$ ). However, in both views, there were no between-group differences in the optimal angles of needle trajectory at the adjacent upper level of the spondylolisthesis. The angle was $1.3 \pm 2.6^{\circ}$ in group $\mathrm{S}$ and $1.8 \pm 2.1^{\circ}$ in group $\mathrm{N}$ (mean difference -0.5 (95\% CI (-) 2.1 to 1.0$), P=0.49$ ) in the transverse midline view, and it was $1.4 \pm 3.9^{\circ}$ in group $\mathrm{S}$ and $1.9 \pm 1.6^{\circ}$ in group $\mathrm{N}$ (mean difference 1.0 (95\% CI (-) 2.4 to 1.5$), P=0.62$ ) in the parasagittal oblique view.

The interlaminar height of the LFD, depths from the skin to the LFD and to AC, and width of the intrathecal space were comparable between the two groups at both levels (Table 3). Figure 3 shows the schematic images representing the optimal angle of needle trajectory of groups $\mathrm{N}$ and $\mathrm{S}$.

The depth from the skin to the LFD and AC and width of the intrathecal space at each level in group $S$ are shown
Table 1 Patient demographics

\begin{tabular}{|c|c|c|}
\hline & $\begin{array}{l}\text { No } \\
\text { Spondylolisthesis } \\
(\mathrm{N}=20)\end{array}$ & $\begin{array}{l}\text { Spondylolisthesis } \\
(\mathrm{N}=20)\end{array}$ \\
\hline Female sex, $\mathrm{N}$ & $17(85)$ & $17(85)$ \\
\hline Age, yr & $66.1(9.7)$ & $66.8(9.9)$ \\
\hline Height, cm & $158.4(8.0)$ & $156.3(7.5)$ \\
\hline Weight, kg & $64.0(11.0)$ & $64.6(8.0)$ \\
\hline $\mathrm{BMI}, \mathrm{kg} / \mathrm{m}^{2}$ & $25.4(3.3)$ & $26.4(2.8)$ \\
\hline \multicolumn{3}{|l|}{ ASA class, $\mathrm{N}$} \\
\hline 1 & $5[25]$ & $6(30)$ \\
\hline$\|$ & $13(75)$ & $12(60)$ \\
\hline III & $2[10]$ & $2[10]$ \\
\hline \multicolumn{3}{|l|}{ Comorbidities, $\mathrm{N}$} \\
\hline Hypertension & $11(55)$ & $11(55)$ \\
\hline Diabetes mellitus & $3(15)$ & $4(20)$ \\
\hline Coronary artery disease & $2(10)$ & $5(25)$ \\
\hline Cerebrovascular disease & $1(5)$ & $1(5)$ \\
\hline Chronic liver disease & $2(10)$ & $2(10)$ \\
\hline Chronic kidney disease & $3(15)$ & $1(5)$ \\
\hline Pulmonary disease & $2(10)$ & $1(5)$ \\
\hline Others & $3(15)$ & $0(0)$ \\
\hline \multicolumn{3}{|l|}{ Spinal abnormality, N } \\
\hline Spondylosis & $15(75)$ & $14(70)$ \\
\hline Scoliosis & $5(25)$ & $5(25)$ \\
\hline Compression fracture & $1(5)$ & $4(20)$ \\
\hline Other abnormality & $7(35)$ & $7(35)$ \\
\hline \multicolumn{3}{|c|}{ Level of spondylolisthesis, $\mathrm{N}$} \\
\hline L3 on L4 & - & 4 \\
\hline L4 on L5 & - & 7 \\
\hline L5 on S1 & - & 9 \\
\hline
\end{tabular}

Categorical data were compared using $\mathrm{x}^{2}$ test, and presented as numbers and percentages

Continuous data presented as median (IQR) or number (\%) of patients

in Table 4. There were no statistically significant differences in the depths from skin to intrathecal space at the two levels.

\section{Discussion}

In this study, we used ultrasonography to evaluate the optimal angle of needle trajectory during spinal anesthesia in patients with spondylolisthesis. We found that the optimal spinal needle insertion at the level of the spondylolisthesis was in a caudad direction, contrary to that observed in patients without spondylolisthesis.

There have been many studies on anatomical considerations that facilitate spinal anesthesia in patients with lumbar spinal deformities; these studies have used imaging modalities such as computed tomography (CT), magnetic resonance imaging (MRI), and ultrasonography $[11,15]$. Among these modalities, ultrasonography has 
Table 2 Optimal angle of needle trajectory at spondylolisthesis level and one upper level

\begin{tabular}{|c|c|c|c|c|c|}
\hline & Level & $\mathbf{N}$ & Normal & Spondylolisthesis & $P$ value \\
\hline \multicolumn{6}{|l|}{ Spondylolisthesis level } \\
\hline \multirow[t]{4}{*}{ Angle in transverse midline view $\left({ }^{\circ}\right)$} & Total & 20 & $0.8 \pm 2.5$ & $-2.7 \pm 3.4$ & \multirow[t]{4}{*}{$<0.001$} \\
\hline & $\mathrm{L} 3 / 4$ & 4 & $1.5 \pm 1.0$ & $-2.5 \pm 3.7$ & \\
\hline & $\llcorner 4 / 5$ & 7 & $2.6 \pm 1.3$ & $-1.7 \pm 3.4$ & \\
\hline & L5/S1 & 9 & $-0.9 \pm 2.7$ & $-3.1 \pm 3.5$ & \\
\hline \multirow[t]{4}{*}{ Angle in Parasagittal oblique view ( ${ }^{\circ}$ ) } & Total & 20 & $1.0 \pm 3.2$ & $-2.7 \pm 4.5$ & \multirow[t]{4}{*}{0.004} \\
\hline & $\llcorner 3 / 4$ & 4 & $2.0 \pm 1.7$ & $-1.0 \pm 6.4$ & \\
\hline & $\llcorner 4 / 5$ & 7 & $2.7 \pm 1.9$ & $-1.7 \pm 4.1$ & \\
\hline & L5/S1 & 9 & $-0.8 \pm 3.8$ & $-4.4 \pm 3.8$ & \\
\hline \multicolumn{6}{|l|}{ Upper level } \\
\hline \multirow[t]{4}{*}{ Angle in transverse midline view $\left({ }^{\circ}\right)$} & Total & 20 & $1.8 \pm 2.1$ & $1.3 \pm 2.6$ & \multirow[t]{4}{*}{0.49} \\
\hline & L3/4 & 4 & $1.6 \pm 2.0$ & $1.9 \pm 2.0$ & \\
\hline & $\llcorner 4 / 5$ & 7 & $2.6 \pm 2.5$ & $0.9 \pm 2.8$ & \\
\hline & L5/S1 & 9 & $1.3 \pm 2.0$ & $1.2 \pm 3.0$ & \\
\hline \multirow[t]{4}{*}{ Angle in Parasagittal oblique view $\left({ }^{\circ}\right)$} & Total & 20 & $1.9 \pm 1.6$ & $1.4 \pm 3.9$ & \multirow[t]{4}{*}{0.62} \\
\hline & L3/4 & 4 & $2.0 \pm 1.4$ & $4.3 \pm 2.2$ & \\
\hline & $\llcorner 4 / 5$ & 7 & $2.6 \pm 1.7$ & $0.9 \pm 3.9$ & \\
\hline & L5/S1 & 9 & $1.4 \pm 1.7$ & $0.6 \pm 4.3$ & \\
\hline
\end{tabular}

Data presented as mean $\pm S D$

P-values are the results of student-T test for continuous variables

Table 3 The ultrasound data at spondylolisthesis level and one upper level

\begin{tabular}{|c|c|c|c|c|}
\hline & & Normal & Spondylolisthesis & $P$ value \\
\hline \multicolumn{5}{|l|}{ Spondylolisthesis level } \\
\hline \multirow[t]{3}{*}{ Transverse midline view } & Depth to LFD, cm & $4.2 \pm 0.7$ & $4.0 \pm 0.6$ & 0.50 \\
\hline & Depth to AC, cm & $5.4 \pm 0.6$ & $5.3 \pm 0.7$ & 0.82 \\
\hline & LFD to $A C, \mathrm{~cm}$ & $1.2 \pm 0.3$ & $1.3 \pm 0.3$ & 0.22 \\
\hline \multirow[t]{4}{*}{ Parasagittal oblique view } & Interlamina height of LFD, cm & $2.1 \pm 0.9$ & $1.8 \pm 1.1$ & 0.63 \\
\hline & Depth to LFD, cm & $3.9 \pm 0.5$ & $3.8 \pm 0.4$ & 0.28 \\
\hline & Depth to AC, cm & $5.1 \pm 0.6$ & $5.1 \pm 0.6$ & 0.67 \\
\hline & LFD to $A C, \mathrm{~cm}$ & $1.2 \pm 0.2$ & $1.3 \pm 0.4$ & 0.13 \\
\hline \multicolumn{5}{|l|}{ Upper level } \\
\hline \multirow[t]{3}{*}{ Transverse midline view } & Depth to LFD, cm & $4.1 \pm 0.7$ & $4.1 \pm 0.6$ & 0.83 \\
\hline & Depth to AC, cm & $5.3 \pm 0.7$ & $5.5 \pm 0.9$ & 0.43 \\
\hline & LFD to $A C, \mathrm{~cm}$ & $1.2 \pm 0.2$ & $1.4 \pm 0.5$ & 0.16 \\
\hline \multirow[t]{4}{*}{ Parasagittal oblique view } & Interlamina height of LFD, cm & $1.1 \pm 0.4$ & $1.0 \pm 0.4$ & 0.18 \\
\hline & Depth to LFD, cm & $4.2 \pm 0.5$ & $4.3 \pm 0.6$ & 0.69 \\
\hline & Depth to $\mathrm{AC}, \mathrm{cm}$ & $5.6 \pm 0.6$ & $5.6 \pm 0.8$ & 0.68 \\
\hline & LFD to $A C, \mathrm{~cm}$ & $1.3 \pm 0.4$ & $1.3 \pm 0.4$ & 0.82 \\
\hline
\end{tabular}

Data presented as mean \pm SD

P-values are the results of student-T test for continuous variables

proved its usefulness in visualizing the interlaminar space especially in patients with abnormal spinal anatomy [4, 16-18]. Spondylolisthesis is one of the most common degenerative spinal deformities, with an incidence of up to $30 \%$ in individuals over the age of $65[19,20]$. To the best of our knowledge, this is the first ultrasonographic study on the optimal angle of needle insertion for spinal anesthesia in patients with spondylolisthesis. If possible, it would be better not to perform a spinal puncture at a level with spondylolysis. However, in older adults, 

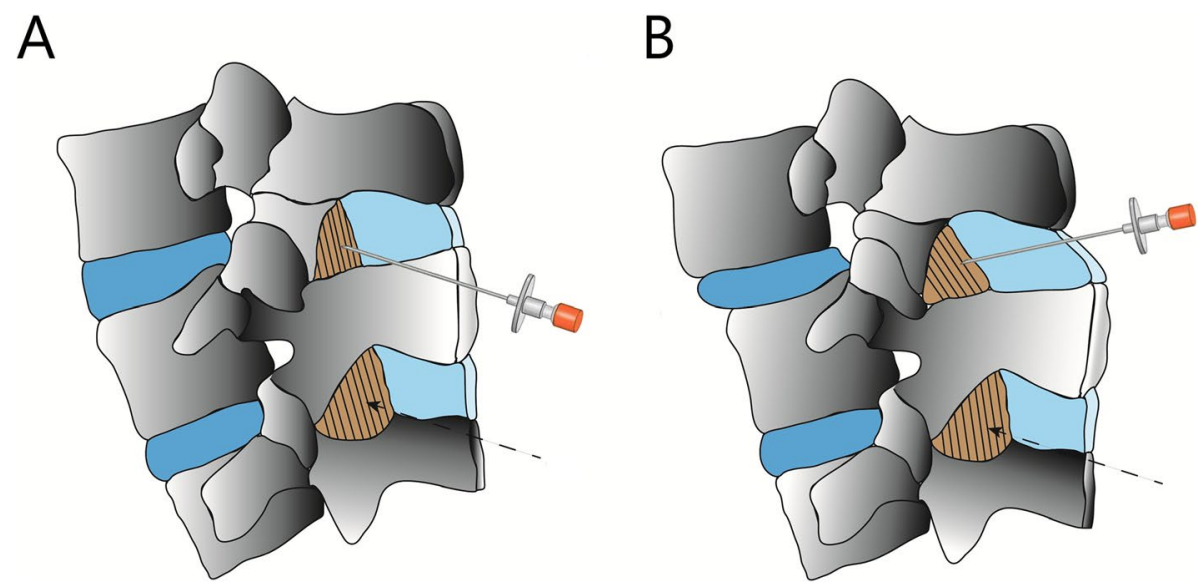

Fig. 3 Schematic image of spinal anesthesia. Schematic image of trajectory of spinal needle to normal spine (A) and spine with lumbar spondylolisthesis (B). The figure represents parasagittal oblique approach of spinal anesthesia. Spinal needle is inserted in a cephalad direction for normal spine (A), while in a slightly caudal direction for spondylolisthesis level (B)

Table 4 Depth from skin to subarachnoid space in spondylolisthesis patients

\begin{tabular}{lllll}
\hline & & Upper level & Spondylolisthesis level & P-value \\
\hline Transverse midline & Depth to LFD (cm) & $4.3 \pm 0.6$ & $4.0 \pm 0.6$ & 0.12 \\
& Depth to AC (cm) & $5.6 \pm 0.8$ & $5.3 \pm 0.7$ & 0.20 \\
Parasagittal oblique & LFD to AC (cm) & $1.3 \pm 0.4$ & $1.3 \pm 0.3$ & 0.97 \\
& Depth to LFD (cm) & $4.1 \pm 0.6$ & $3.8 \pm 0.4$ & 0.07 \\
& Depth to AC (cm) & $5.5 \pm 0.9$ & $1.3 \pm 0.6$ & 0.12 \\
\hline
\end{tabular}

Data presented as mean \pm SD

P-values are the results of student-T test for continuous variables

spondylolisthesis is often accompanied at more than one lumbar level, and other spinal deformities can be accompanied at other levels. In such cases, the anesthesiologist might have to perform spinal puncture at a level with spondylolisthesis.

Conventionally, when performing spinal anesthesia using the midline or paramedian approach, the angle of needle insertion is often in a slightly cephalad direction according to the anatomy of the lumbar spinous process, which projects from the cephalad to the caudad direction. A previous study recommended a midline approach with a cranial angle of the needle to the dorsal plane of the skin of $90-110^{\circ}$ [21]. and a cranial angle of the paramedian needle to the dorsal plane of the skin of $120-135^{\circ}$ [22]. Vogt et al. analyzed the spine CT images of 52 patients without any structural anomaly and estimated that the optimal angles for needle insertion for spinal puncture at both the L3/4 and L4/5 levels were 9 degrees in the cephalad direction [23]. Another study by Puigdellívol-Sánchez [24] revealed that the angles from the axial plane to the skin passing above the inferior spinous process on the spinal MRIs of seven individuals were $9.0^{\circ}$ and $8.9^{\circ}$ at $\mathrm{L} 3 / 4$ and $\mathrm{L} 4 / 5$, respectively. However, our results showed that cephalad angulation of the spinal needle cannot be applied for spinal puncture at the level of the spondylolisthesis.

Since the upper vertebral body slides down along the superior endplate of the lower vertebral body in patients with spondylolisthesis, the angle of spinal needle insertion may need to be altered for successful spinal puncture (Fig. 3). According to our results, a caudad angulation is needed during needle insertion for spinal anesthesia at the level of the spondylolisthesis.

Notably, in both groups, the optimal needle insertion angle at the L5/S1 level tended to be more caudad-oriented than that at other levels, in both groups. Funao et al. [25] assessed the spinopelvic alignment of patients with and without spondylolisthesis using standing lateral radiographs. They reported that the sacral slope the angle between the superior endplate of S1 and the horizontal plane - was much steeper than the L4 or L5 slope - the angle between the superior endplate of L4 
or L5 and the horizontal plane - in groups with and without spondylolisthesis. Besides, Chen et al. retrospectively compared lumbar spine $\mathrm{CT}$ images between control and degenerative spondylolisthesis group, and found out that a large angle of sacral slope is a risk factor of L5 degenerative spondylosis [26]. As shown in previous researches, the steep angle of sacral slope may explain the more caudal angle of needle insertion at L5/ S1 level.

There were no between-group differences in the interlaminar height of the LFD and width of the intrathecal space, regardless of the level. This suggests that even in patients with spondylolisthesis, the difficulty of spinal anesthesia may not increase significantly if the needle is inserted at the optimal angle.

This study has several limitations. First, the anesthesiologist who performed the ultrasonography was not completely blinded to the group allocation. This was inevitable because structural abnormalities could be visually identified during ultrasound scanning on the patient's back. Second, the accuracy of measurements of small angles or distances with ultrasound is likely inspectordependent and has some built in error. The possibility of systematic error of measurements exists since the measurements are small. Third, the difference in angulation that we found was only about 3 degrees. Although this is small, the fact that the needle direction is changed from cephalad to caudad is clinically meaningful. The reason for the small difference in angle may be because all of the patients enrolled in this study were low grade spondylolisthesis patients. For patients with spondylolisthesis of a higher grade, the optimal angle of needle insertion may differ, and a larger caudad angulation may be required in them. Fourth, without information about spondylolisthesis from pre-operative lumbosacral X-ray image, it may be difficult to apply the results of this study to the patient. Ultrasonography may be helpful in this situation. Finally, we estimated the optimal angle of needle insertion using an ultrasound probe but did not actually perform spinal puncture. Since this study is observational, further study is necessary to determine the difference in clinical outcomes when this technique is applied on patients.

\section{Conclusions}

In conclusion, anesthesiologists should consider the fact that the optimal angle for needle insertion for spinal anesthesia is more caudad at the level of a spondylolisthesis than at other levels or in patients without spondylolisthesis. This phenomenon is most prominent at the L5/S1 level.
Abbreviations

LFD: Ligamentum flavum-dura mater complex; AC: Anterior complex; CT: Computed tomography; MRI: Magnetic resonance imaging.

\section{Acknowledgements \\ Not applicable.}

\section{Authors' contributions}

Y Kim, MD:: This author helped recruit the patients, collect and analyze the data, and draft the final manuscript. S Yoo, MD.: This author helped recruit the patients, and collect the data. S-K Park, MD.: This author helped analyze the data. H Bae, MD.: This author helped collect the data. Y-J Lim, MD, PhD: This author helped revise the final manuscript. J-T Kim, MD, PhD.: This author helped design the study, recruit the patients, collect and analyze the data, and draft the final manuscript. The author(s) read and approved the final manuscript.

\section{Funding}

The authors have no sources of funding to declare for this manuscript.

\section{Availability of data and materials}

The datasets used and/or analyzed during the current study are available from the corresponding author on reasonable request.

\section{Declarations}

Ethics approval and consent to participate

:This study was approved by the Institutional Review Board of Seoul National University Hospital (IRB No. 2005-149-1125) and written informed consent was obtained from all subjects prior to participation.

\section{Consent for publication}

Not applicable.

\section{Competing interests}

The authors declare that they have no competing interests.

\section{Author details}

${ }^{1}$ Department of Anesthesiology and Pain Medicine, Seoul National University Hospital, Seoul National University College of Medicine, Daehak-ro, Jongno-gu, Seoul, Korea 03080. ${ }^{2}$ Department of Anesthesiology and Pain Medicine, Dongguk University Ilsan Hospital, 27 Dongguk-ro, Ilsandong-gu, Goyang-si, Gyenggi-do, Korea 10326

Received: 26 March 2021 Accepted: 28 August 2021

Published online: 08 September 2021

\section{References}

1. Chin KJ, Perlas A, Chan V, Brown-Shreves D, Koshkin A, Vaishnav V. Ultrasound imaging facilitates spinal anesthesia in adults with difficult surface anatomic landmarks. Anesthesiology. 2011;115(1):94-101.

2. KallidaikurichiSrinivasan K, lohom G, Loughnane F, Lee PJ. Conventional Landmark-Guided Midline Versus Preprocedure UltrasoundGuided Paramedian Techniques in Spinal Anesthesia. Anesth Analg. 2015;121(4):1089-96.

3. Yoo S, Kim Y, Park SK, Ji SH, Kim JT. Ultrasonography for lumbar neuraxial block. Anesth Pain Med (Seoul). 2020;15(4):397-408.

4. Chin KJ, Perlas A, Chan V. The ultrasound-assisted paraspinous approach to lumbar neuraxial blockade: a simplified technique in patients with difficult anatomy. Acta Anaesthesiol Scand. 2015;59(5):668-73.

5. Gropper MA, Miller RD, Eriksson LI, Fleisher LA, Wiener-Kronish JP, Cohen NH, et al. Miller's Anesthesia, 9E: Elsevier Health Sciences; 2019.

6. Chuang CY, Liaw MY, Wang LY, Huang YC, Pong YP, Chen CW, et al. Spino-pelvic alignment, balance, and functional disability in patients with low-grade degenerative lumbar spondylolisthesis. J Rehabil Med. 2018:50(10):898-907. 
7. Ruzman T, Gulam D, HarsanjiDrenjancevic I, Venzera-Azenic D, Ruzman N, Burazin J. Factors associated with difficult neuraxial blockade. Local Regional Anesthesia. 2014;7:47-52.

8. Inoue S, Kawaguchi M, Furuya H. Successful spinal administration is related to the angle formed between the skin and a spinal needle. A geometric model. Anaesthesia Intensive Care. 2011;39(4):770-1.

9. Wang YXJ, Káplár Z, Deng M, Leung JCS. Lumbar degenerative spondylolisthesis epidemiology: A systematic review with a focus on genderspecific and age-specific prevalence. J Orthop Translat. 2017:11:39-52.

10. Erbas YC, Pusat S, Yilmaz E, Bengisun ZK, Erdogan E. Posterior Lumbar Stabilization Surgery under Spinal Anesthesia for High-Risk Patients with Degenerative Spondylolisthesis, Spinal Stenosis and Lumbar Compression Fracture. Turk Neurosurg. 2015;25(5):771-5.

11. Bae J, Park SK, Yoo S, Lim YJ, Kim JT. Influence of age, laterality, patient position, and spinal level on the interlamina space for spinal puncture. Regional Anesthesia Pain Med. 2019.

12. Kim EH, Lee JH, Song IK, Kim HC, Kim HS, Kim JT. Influence of caudal traction of ipsilateral arm on ultrasound image for supraclavicular central venous catheterization. Am J Emerg Med. 2016;34(5):851-5.

13. Lim KJ, Lee JM, Byon HJ, Kim HS, Kim CS, Lee SK, et al. The effect of full expiration on the position and size of the subclavian vein in spontaneously breathing adults. Anesth Analg. 2013;117(1):109-13.

14. Koslosky E, Gendelberg D. Classification in Brief: The Meyerding Classification System of Spondylolisthesis. Clin Orthop Relat Res. 2020;478(5):1125-30.

15. Park SK, Yoo S, Kim WH, Lim YJ, Bahk JH, Kim JT. Ultrasound-assisted vs landmark-guided paramedian spinal anaesthesia in the elderly: A randomised controlled trial. Eur J Anaesthesiol. 2019;36(10):763-71.

16. Chin KJ, Ramlogan R, Arzola C, Singh M, Chan V. The utility of ultrasound imaging in predicting ease of performance of spinal anesthesia in an orthopedic patient population. Reg Anesth Pain Med. 2013;38(1):34-8.

17. Perlas A, Chaparro LE, Chin KJ. Lumbar Neuraxial Ultrasound for Spinal and Epidural Anesthesia: A Systematic Review and Meta-Analysis. Reg Anesth Pain Med. 2016:41(2):251-60.

18. Park SK, Bae J, Yoo S, Kim WH, Lim YJ, Bahk JH, et al. Ultrasound-Assisted Versus Landmark-Guided Spinal Anesthesia in Patients With Abnormal
Spinal Anatomy: A Randomized Controlled Trial. Anesth Analg. 2020;130(3):787-95.

19. Jacobsen S, Sonne-Holm S, Rovsing H, Monrad H, Gebuhr P. Degenerative lumbar spondylolisthesis: an epidemiological perspective: the Copenhagen Osteoarthritis Study. Spine. 2007;32(1):120-5.

20. Bydon M, Alvi MA, Goyal A. Degenerative Lumbar Spondylolisthesis: Definition, Natural History, Conservative Management, and Surgical Treatment. Neurosurg Clin N Am. 2019;30(3):299-304.

21. Blomberg RG, Jaanivald A, Walther $\mathrm{S}$. Advantages of the paramedian approach for lumbar epidural analgesia with catheter technique. A clinical comparison between midline and paramedian approaches. Anaesthesia. 1989;44(9):742-6.

22. Bonica J. Continuous peridural block. Anesthesiology. 1956;17(4):626-30.

23. Vogt M, van Gerwen DJ, Lubbers W, van den Dobbelsteen JJ, Hagenaars M. Optimal Point of Insertion and Needle Angle in Neuraxial Blockade Using a Midline Approach: A Study in Computed Tomography Scans of Adult Patients. Reg Anesth Pain Med. 2017;42(5):600-8.

24. Puigdellívol-Sánchez A, Reina MA, Sala-Blanch X, Pomés-Talló J, Prats-Galino A. Pythagoras and Cosines: The skin-dural sac distance and optimal angles in paramedian spinal anesthesia. Clin Anat. 2016;29(8):1046-52.

25. Funao H, Tsuji T, Hosogane N, Watanabe K, Ishii K, Nakamura M, et al. Comparative study of spinopelvic sagittal alignment between patients with and without degenerative spondylolisthesis. Eur Spine J. 2012;21(11):2181-7

26. Chen Q, Cao L, Bian C, Wang HR, Lin H, Li XL, et al. Degenerative Spondylolisthesis in the Fifth Lumbar Vertebra and Radiographic Parameters: A Correlation Analysis. Clin Spine Surg. 2017;30(9):E1233-8.

\section{Publisher's Note}

Springer Nature remains neutral with regard to jurisdictional claims in published maps and institutional affiliations.
Ready to submit your research? Choose BMC and benefit from:

- fast, convenient online submission

- thorough peer review by experienced researchers in your field

- rapid publication on acceptance

- support for research data, including large and complex data types

- gold Open Access which fosters wider collaboration and increased citations

- maximum visibility for your research: over $100 \mathrm{M}$ website views per year

At BMC, research is always in progress.

Learn more biomedcentral.com/submissions 